\title{
1 \\ Towards Effective Partnerships for the Development of Small Island States
}

\author{
Cletus I Springer
}

\section{Introduction}

Seminal UN Conferences over the past two decades have shown that a strong consensus has emerged globally about the special circumstances of small island developing states (SIDS). The conferences on Environment and Development (Brazil, 1992), Sustainable Development of Small Island Developing States (Barbados, 1994) and its follow-up meeting in Mauritius (2005), as well as the Commonwealth Secretariat/World Bank Joint Task Force on Small States (2000) agreed that these circumstances are rooted in their economic, social and environmental vulnerability including:

- A high degree of economic openness that makes them highly susceptible to economic conditions in the rest of the world;

- Dependence on a narrow range of exports, giving rise to risks associated with lack of diversification;

- Dependence on strategic imports, in particular energy, construction and industrial supplies, exacerbated by limited import substitution possibilities;

- Insularity, peripherality and remoteness, leading to high transport costs and marginalisation from the main commercial centres (Briguglio, 2004);

- Small populations and thin markets which constrain their efforts to reap the benefits of economies of scale, and which lead to high infrastructural, administrative and other overhead costs, and pose additional constraints such as limited attraction for foreign direct investment (FDI);

- A high degree of susceptibility to geophysical events such as floods, droughts, storms, hurricanes, and earthquakes; and

- Vulnerability of biological resources to natural and industrial disasters. 
Moreover, it is accepted that (i) small size engenders natural monopolies and oligopolistic structures in SIDS leading to high consumer costs and that (ii) transforming a government monopoly to private business may even make matters worse, due to the fact that private business is often less accountable to consumers than the public sector.

It is acknowledged within and among SIDS, as well as among actors in the international development community, that the development challenges facing SIDS cannot be addressed in a vacuum. Development requires an institutional architecture for integrated development planning that allows SIDS to manage their respective economic, infrastructural and environmental assets and spaces within a culture of co-operation, collaboration and partnership at local, national, regional and international levels.

This chapter reviews the progress that has been made nationally, regionally and internationally in promoting the practice of partnerships for small states' development. The chapter is set out in four sections. After the introduction the second section briefly explores the roots and branches of the partnership concept. The third section highlights select areas of progress and challenge with partnerships at the national, regional and international levels and offers some policy recommendations for overcoming such challenges and advancing progress. A fourth section concludes the chapter.

\section{Notions of partnership}

Partnerships are commonly defined as 'voluntary and collaborative relationships between state and non-state parties, in which all participants agree to work together to achieve a common purpose or undertake a specific task and to share risks, responsibilities, resources, competencies and benefits' (2005 Report of the UN Secretary-General, to UN General Assembly, A/60/214, para 8, pp. 4). Generally, partnerships seek to identify common interests between actors in the development process at the national, regional and international level and to combine the resources of these actors towards the attainment of agreed development objectives. Partnerships may focus on the many areas where private actors and public institutions can engage in mutually beneficial relationships, such as poverty reduction, health, education and environmental sustainability. Effective partnerships may enable development actors to:

- Overcome challenges that are too difficult or complex for one country, organisation or sector to address by itself;

- Increase the effectiveness and impact of policy interventions and resource inputs;

- Better achieve their own individual objectives through leveraging, combining and capitalising on complementary strengths and capabilities; and

- Leverage support for implementation of development programmes.

The UN identifies three broad types of partnerships:

(a) Core business partnerships in which partners collaborate to create employment and foster entrepreneurship, contribute to economic growth, generate tax revenues, implement social, environmental or ethical standards and provide appropriate and affordable goods and services. 
(b) Social investment and philanthropy partnerships in which the private sector and non-profit organisations provide financial support, contribute volunteers or expertise, or make in-kind contributions, including product donations.

(c) Advocacy and awareness-raising partnerships in which the private sector partners with other stakeholders such as NGOs to take a leadership role in championing, advocating for, and contributing to resolving different issues. In this arrangement, companies often partner with governments and regulatory bodies, and participate in legitimate dialogues and collective action with stakeholders from diverse sectors of the economy.

While recognising the importance of all of the above forms of partnership to the sustainable development of SIDS, this chapter focuses mainly on core business partnerships involving governments, the private sector, non-governmental organisations and international development partners.

\section{The national dimension}

\section{The governance imperative}

It has been theorised that the characteristics of smallness should naturally enable more effective partnerships between and among state and non-state actors and help to forge consensus on development objectives and the manner in which such objectives can be pursued. However, the strength and impact of partnerships at any level depends heavily on several factors such as political culture, and the quality and effectiveness of governance arrangements at the sub-national, national, regional and global levels. The reality is that in most SIDS these objective conditions either do not exist or are not mature enough to support strong and sustained partnership activities. As the Nobel Laureate, Sir Arthur Lewis, noted in his Agony of the Eight, various political, social and cultural tensions exist in small states that can severely weaken the foundation of governance on which effective partnerships are built.

'In a small island dominated by a single party, it is very difficult to prevent political abuse. Everybody depends on the government for something, however small, so most are reluctant to offend it. The civil servants live in fear; the police avoid unpleasantness; the trade unions are tied to the party; the newspaper depends on government advertisements; and so on. This is true even if the political leaders are absolutely honest. In cases where there are corrupt and play with public funds the situation becomes intolerable' (Lewis, 1965).

A review of the literature reveals greater clarity about how governance works than about what it is. The Organisation for Economic Co-operation and Development (OECD, n.d.) believes that governance and government go hand in hand and that:

'Good effective public governance helps to strengthen democracy and human rights, promote economic prosperity and social cohesion, reduce poverty, enhance environmental protection and the sustainable use of natural resources and deepen confidence in government and public administration'. ${ }^{2}$

The most widely cited definition of governance is the one articulated by the United Nations Development Programme (UNDP, 1997, p.5) as 'the exercise of economic, political 
and administrative authority to manage a country's affairs at all levels' (UNDP, 1997). In this perspective, governance comprises the mechanisms, processes, and institutions through which citizens and groups articulate their interests, exercise their legal rights, meet their obligations and mediate their differences (Singh, 2003, p.474).

From an aggregation of the various definitions it is clear that governance is a complex, long-term process whose successful outcome is dependent on a variety of factors including: (a) the national political culture; (b) the state of mind of the citizenry, in particular their capacity for self-actualisation, self-empowerment and innovation; (c) the flexibility and responsiveness of the policy and the institutional framework to internal and external stimuli; and (d) respect for human rights and for the rule of law.

This chapter does not set out to address these issues fully and focuses instead on those governance structures and processes that can best support partnerships that are integrated and participatory and that facilitate the requisite consensus building among partners engaged in the national and/or regional development process. Ideally, all partners should share the same vision and should be routinely engaged in a careful examination of development options and the design of clear strategies, programmes and plans for effective mobilisation and utilisation of human, financial, technological and natural resources.

It has been argued that traditional development planning arrangements do not provide adequate space for the active and sustained participation of state and non-state actors in the development process in SIDS. To correct this shortcoming, SIDS have been encouraged to consider Integrated Development Planning (IDP) described as 'a holistic, dynamic and fully participatory approach to development planning that integrates and co-ordinates economic, cultural, social, environmental, demographic, financial and spatial dimensions into the planning process to ensure the effective and sustainable use of available human, financial and natural resources for the benefit of all'. ${ }^{3}$ This approach incorporates social, environmental, physical and economic parameters with the direct involvement of local institutions, stakeholders and political leadership.

The adoption of an integrated approach, linking social, environmental and economic parameters is crucial to the promotion of sustainable development. The separate and combined effects of these parameters have not normally been considered during the planning process in SIDS. Chapter 10 of the Barbados Programme of Action on National Institutions and Administrative Capacity regards the integration of environmental considerations into the national decision-making process as the single most important step to be taken by SIDS to ensure that their environmental problems are addressed and that the principles of sustainability guide all future development. It asserts that economic imperatives must be evaluated from the perspective of socio-environmental considerations if the natural resource base is to be preserved. It advocates the adoption of interdisciplinary approaches to planning and decision-making, as well as the sustained public participation in the process.

Over the past two decades SIDS have attempted to identify and implement various modes of IDP. In most SIDS laws exist that require the participation of civil society representatives on management boards of statutory corporations. Several SIDS governments, including St Lucia, Antigua and Barbuda, Grenada, Barbados and Mauritius, have attempted to broaden participation by non-state actors in the decision-making process. One way in which 
they have achieved this is through the establishment of national sustainable development councils. However, the effectiveness and influence of these arrangements on policy making, as well as their longevity, have tended to be highly sensitive to changes in government. It has been argued that the mere fact that changes in government should engender uncertainty about the fate of a national policy or plan that is the product of broad-based consultations is an indication that the tenets of participatory governance are not deeply rooted and widely shared among the citizenry.

At the same time, new governments have argued that they are under no obligation to continue with the policies or plans of preceding administrations. Neither argument is without merit. However, what is critical is an abiding commitment by all political actors to the principles of participatory governance. Adherence to these principles would oblige any new administration to seek to change existing policies through the same channels and procedures by which the original instrument was created.

Additional challenges to the process of participatory governance include:

- Perceptions among the political directorate that a commitment to consultation and collaboration with non-elected, non-state actors will weaken their political power;

- The influence of electoral cycles on policy and programme design and implementation;

- High levels of partisanship among the citizenry;

- The compartmentalised nature of decision-making in the public sector which does not allow for routine participation by non-state actors and which does not allow for proper analysis of the integrated effects of sectoral policies;

- Weak decision support systems that do not routinely take account of the contribution of natural assets to economic growth and social development and that do not properly track changes in the quantity and quality of these assets;

- Challenges in the use of sustainable development indicators, including a lack of data and development capacity, of international harmonisation efforts, of further indicator development in 'less advanced' substantive areas, and of training in integrated information management (Shah, 2004, p.4); and

- Low capacity among non-state actors to sustain their roles in participatory decisionmaking.

\section{Non-state actors and the governance process}

Civil society ${ }^{4}$ is probably the largest single factor in development, if not in terms of its monetary contribution, in its human contribution and its experience and history (Wolfensohn, 1999). ${ }^{5}$ The capacity of civil society actors and institutions can have a significant bearing on the quality of both the participatory governance process as well as on the outputs and outcomes of that process. To participate effectively in such processes, to reduce the likelihood of stalemates or lopsided outcomes and increase the prospect of consensus through compromise, civil society actors should have a sound grasp of the issues under consideration as well as appropriate negotiating skills.

Historically, there has been very little involvement of civil society in the design, implementation and evaluation stages of development policy. While there has been 
some improvement in recent years, participation by civil society organisations (CSOs) in national and regional governance has tended to be restricted to unique events. Where institutionalised mechanisms for participation exist, the low capacity of CSOs has severely limited their ability to participate effectively in the planning and decision-making process. The heavy dependence of some of these organisations on government subventions has tended to weaken their legitimacy and independence. In addition, the civil society sector tends to be highly fragmented and past attempts to improve co-ordination have met with limited success.

The commitment of politicians to the involvement of civil society in planning and decision-making has frequently been questioned. In some cases, the level of politicisation within civil society itself has militated against sustained and effective civil society participation in planning and decision-making. Also constraining participation is the limited pool of competent participants. Given the small, island nature of SIDS, there has been a tendency for the same people to be repeatedly involved in consultations leading to complaints of consultation fatigue and a lack of post-consultation implementation. Efforts are underway in several SIDS to develop local democratic structures. However, concerns are often expressed as to whether such local structures would increase bureaucracy and costs. Encouragingly, many CSOs have taken steps to strengthen their capability in project design and implementation, which has in turn enabled them to access more financing from traditional and non-traditional sources. Further, many environmental non-governmental organisations (NGOs) at the national, regional and international level are making a more conscious effort to demonstrate the links between conservation, human wellbeing and development.

The private sector in many SIDS faces its own governance challenges which limit its overall impact on development as well as its ability to contribute to decision making. Generally the sector is in poor shape, as reflected by:

- A lack of enforcement of company laws;

- Limited stakeholder participation in companies;

- Limited human resource capabilities in the relevant areas;

- Inadequate treatment of the rights of minority shareholders;

- Ineffective and unclear guidelines for accountability by board members of corporations;

- Poorly equipped judicial systems; and

- A strong interlocking relationship between government and the financial sector.

In addition, the disposition of the private sector towards profit maximisation and its traditionally low regard for environmental sustainability and for workers' rights has tended to create an antagonistic relationship between it and environmental groups. In recent years the relationship between the private sector and governments on the one hand and NGOs on the other has begun to improve under a growing awareness that there is no inherent, absolute contradiction between corporate survival and human survival. Many businesses in SIDS have begun to embrace corporate social responsibility (CSR), defined by the World Business Council for Sustainable Development (WBCSD) as 'the continuing commitment by a business to behave ethically and contribute to economic development while improving 
the quality of life of the workforce, their families and the local community and society at large' (WBCSD 1998, p.3). Increasingly, CSR is being seen by firms and businesses as a formula for long-term success, a means of helping to create a more inspired workforce and a more rewarding working environment and as a means of bonding with consumers and host communities. However, CSR is deemed to have been achieved only when a business adapts its practices to ensure that it operates in ways that meet or exceed the ethical, legal, commercial and public expectations that society has of that business. In this regard, it can be said that the private sector in many SIDS has some way yet to go before it can be described as a firm adherent to the CSR ethic.

Given these significant challenges facing the development partners at the national level, it is perhaps unreasonable to expect anything more than measured, moderate progress in the formation of true and firm partnerships and in the establishment and effective functioning of IDP arrangements in particular and participatory governance in general in SIDS.

\section{The regional dimension}

Partnership is implied in the very notion of regionalism, that is, a process wherein two or more entities undertake to co-operate with each other, over one or more aspects of their individual and mutual development. The fact that many SIDS are embracing regionalism as a means of mitigating the constraints posed by smallness means that effective IDP at a supranational level is also critical. For example, member countries of the Pacific Island Forum (PIF) have committed to a South Pacific Regional Trade and Economic Cooperation Agreement (SPARTECA), a non-reciprocal agreement in which two developed countries Australia and New Zealand - offer duty-free, unrestricted and/or concessional access for almost all products originating from other PIF Member States. ${ }^{6}$ Caribbean Community (CARICOM) SIDS have committed to the establishment of a Single Market and Economy (CSME), details of which are shown in Box 1.1.?

The same strictures and weaknesses identified with participatory governance and IDP at the national level also exist at the regional level. Regional intergovernmental arrangements in SIDS such as the OECS and CARICOM (in the Caribbean) and the PIF for the most part constitute partnerships among governments. The decision-making structures of these organisations provide limited opportunity for meaningful, sustained participation by civil society organisations. In the case of CARICOM, there is partial involvement of labour and the private sector in meetings of various organs such as the Council on Trade and Economic Development (COTED) and of heads of government. However, as Lewis (2003, p. 523-524) has noted, a deepening, widening and strengthening of participatory arrangements is now being demanded by the following circumstances:

- The changing nature of regional economic integration such that the creation of a single market in combination with market liberalisation of the wider environment calls for a larger role for the private sector as opposed to the state sector and for a more formal integration of this sector into the policy design and implementation process;

- The focus on labour and environment as significant issues within the World Trade Organization (WTO) negotiation process; and 


\section{Box 1.1 The Caribbean Single Market and Economy (CSME)}

The centrepiece of CARICOM's trade and economic development policy is the CSME. It aims to reconstitute 15 formerly separate and distinct economies into a single economic space. In the process, it will alter the trajectory of their development and their relationship with each other and with other economic systems in the rest of the world. The raison d'être for the CSME is underpinned by the Revised Treaty of Chaguaramas, which envisages that the respective markets of the Caribbean shall be reconstituted as a single market by the removal of existing barriers, not only to the trade in goods, but to the trade in services, capital flows, technology; the free movement of skilled persons; and the right of establishment of enterprise anywhere in the region. The Revised Treaty also provides for the reconfiguration of the separate domestic economies into a single economy through:

- The harmonised co-ordination and convergence of macroeconomic policy;

- The implementation of common external trade policy;

- The harmonisation and co-ordinated development of the productive economic sectors and small and micro-enterprises;

- Collaboration in relation to the management of monetary and exchange rate affairs;

- Joint regional actions in relation to the development of capital markets, standards setting and enforcement of a community-wide competition policy and consumer protection measures; and

- The creation of new regional institutions to implement regional policies in the related areas.

In pursuit of the objective of equitable development, the Revised Treaty makes specific allowance to accord special and differential treatment to those countries, especially in the OECS, that enter the process as less developed countries (LDCs). It also sets out the processes by which countries, regions or sectors which experienced disadvantages as a result of the workings of the regional integration process can seek and attain redress. To bolster consumer and investor confidence in the certainty, predictability and fairness in the application of measures relating to the CSME, new modes of mediation and dispute settlement have been embedded in the Revised Treaty, to be applied by the Caribbean Court of Justice (CCJ), which has been vested with the compulsory and exclusive jurisdiction to hear and determine disputes concerning the interpretation of the Revised Treaty. Chapter 4 of the Revised Treaty reflects the wide-ranging, intersectoral nature of the CSME. It outlines areas for co-operation in the articulation and implementation of policies and programmes for sectoral development, including:

- A charter for micro and small economic enterprise development;

- A common agriculture policy;

- A framework for regional human resources development;

- Regional technological programmes;

- A community investment policy;

- A policy for environmental and intellectual property protection; and

- Harmonised legislation in areas such as investment incentives, customs, taxation, companies and competition policy.

As part of the CSME process, a number of new regional institutions are required, including:

- A Regional Competition Commission;

- A Caribbean Regional Organisation for Standards and Quality;

- A Regional Accreditation Unit; and

- A Regional Development Fund. 
- The continuing engagement of governments in international economic negotiations requires an established 'knowledge techno-structure' for providing appropriate information and for designing appropriate negotiating strategies, roles that to some extent have been fulfilled by the Caribbean Regional Negotiating Machinery (CRNM).

Lewis' observations are supported by Byron (2003, p.75) who calls for different models of political units to be explored to maximise community and societal participation including with diasporic communities and to strengthen the economic viability of SIDS. It is unclear how CARICOM intends to facilitate the sustained participation of civil society that is necessary to give full effect to the provisions of Chapter 4 of the Revised Treaty of Chaguaramas as they relate to initiatives such as the design of a charter for small and medium enterprises (SMEs). What is clear is that current avenues such as the COTED are not adequate for this purpose.

The absence of effective participation by opposition parties and civil society in regional governance arrangements has long been recognised as a serious constraint to the emergence of meaningful development partnerships in SIDS. Recognition of this fact is reflected in the adoption in 1997 by CARICOM Heads of Government of a Charter on Civil Society (COCS) and their decision in 1996 to establish an Assembly of Caribbean Community Parliamentarians (ACCP). The Charter is made up of 27 articles that define the civil, political, economic, social and cultural rights of Caribbean citizens, while generally promoting racial harmony, sustainable development and economic growth. ${ }^{8}$ In the document CARICOM heads pledged their commitment 'to create a truly participatory political environment within the Caribbean Community which will be propitious to genuine consultation in the process of governance'. Two major weaknesses in the Charter include its definition of social partners as those entities 'recognised by the State' - a requirement which the Centre for International Environmental Law (CIEL, 2003:5) rightly regards as a top-down, positivist definition which carries the potential for discrimination of disfavoured groups and marginalisation of groups without the means to institutionalise. ${ }^{9}$ A second weakness is its failure to address the participation of civil society within the governance of CARICOM itself. The Liliendaal Statement of Principles adopted at a Civil Society 'Forward Together' Conference held in Guyana in July 2002, tackles this weakness in acknowledging that 'Civil society has a vital role to play in the development of regional, political and social policies, the development of those programmes and frameworks currently in existence, their modification, where necessary, and the creation of new areas as required'. ${ }^{10}$

The ACCP has not fared much better. A Prime Ministerial Expert Group on Governance (PMEGG) established in 2003, recommended that (a) the ACCP should be strengthened to ensure that it functioned as an authentic regional body; (b) it should continue to function as a consultative and deliberative body; (c) its members should comprise both government and opposition parliamentarians; and (d) its observers should be expanded to cater for the participation of civil society organisations. However, by 2006 a Technical Working Group on Governance established by CARICOM Heads of Government encouraged that the recommendations of the PMEGG be implemented. ${ }^{11}$ 
The weaknesses in the governance arrangements in CARICOM also apply, albeit in smaller measure to the member countries of the PIF, 14 of which have committed to the Pacific Island Countries Trade Agreement (PICTA) which aims to establish a Free Trade Area for goods. Under Initiative 12.3 of the Pacific Plan, the PIF aims to pursue a good governance programme that covers work on harmonisation of traditional and modern governance values and structures, traditional courts, media, freedom of information, parliamentary effectiveness, peace building and conflict resolution, landownership models, tenure and use, good governance education and governance indicators. ${ }^{12}$ The PIF has recognised the importance of engaging in regular dialogue with the private sector and supported the design and implementation of a private sector development strategy, which in turn led to the formation in 1996 of a Pacific Islands Private Sector Organisation (PIPPSO) to represent the private sector at regional level, public-private sector dialogue, as well as to build the capacity of national private sector organisations and strengthen their role during in-country consultative processes.

The lack of effective private sector participation in national and regional governance accounts in part for the low level of public-private sector partnerships in financing the implementation of development programmes. The two sectors continue to function largely from separate domains. Examples of investments by the private sector in public sector investment projects are connected mainly with: Build, Own, Lease and Transfer (BOLT) and Build Own, Operate and Transfer (BOOT) schemes; joint financing of regional tourism marketing campaigns and in land-development schemes. However, even in these areas, private sector participation is led primarily by the banking sector. Public-private sector partnerships in non-financial spheres, such as education, social development, environmental conservation, and crime management are increasing, but primarily in a philanthropic context. The University of the South Pacific (USP) and the University of the West Indies (UWI) are prime beneficiaries of private sector largesse through endowments, research grants and funded chairs.

The private sector in SIDS is even less active in international sustainable development events and follow-up initiatives. This is partly due to the fact that such events are structured and promoted as government-only events. This is certainly the case with the Multilateral Environmental Agreements, which are negotiated in Conferences of the Parties in which the 'parties' are exclusively governments. Additionally, most private sector actors in SIDS are small businesspersons who are unable to devote the time and resources to attending meetings in distant world capitals. As a consequence, the private sector in SIDS has been slow to react to trends in many critical sustainable development issues such as climate change, sustainable manufacturing, and renewable energy technologies. This also accounts for the private sector's low uptake of the benefits of the Clean Development Mechanism (CDM) - an environmental investment and credit scheme which is intended to spur low-carbon development by allowing a country with an emission-reduction or emission-limitation commitment under the Kyoto Protocol (Annex B Party) to implement an emission-reduction project in developing countries. Such projects can earn saleable certified reduction credits each equivalent to one tonne of $\mathrm{CO} 2$, which can be counted towards meeting the targets of the Kyoto Protocol. ${ }^{13}$ 


\section{The international dimension}

Over the past two decades there have been encouraging developments on several fronts in global partnerships, involving and benefiting SIDS, triggered in part by global issues such as HIV/AIDS, environment, climate change and natural disasters, food security, water security and poverty, and sustained by seminal global events such as the UN Conferences on Environment and Development, on Sustainable Development and on Climate Change (which produced Agenda 21, the Johannesburg Plan of Implementation and the Climate Change Convention and the Kyoto Protocol respectively); and the Millennium Summit which produced the Millennium Development Goals (MDGs). Nearly all the major intergovernmental organisations have devised policies and mechanisms to promote the sustained involvement and participation of the private sector in regional and global initiatives. Included among these mechanisms are regional networks which increasingly playing important roles in sharing and harmonising best practices, and facilitating co-ordination among state and non-state actors.

Generally, these developments have helped to galvanise stronger global awareness of the relevant issues and a growing commitment by international development partners to respond in tangible ways including through new - though not additional - financing for various causes such as the Global Fund to Fight Aids (GFFA) and the Global Environment Facility (GEF). There is a growing recognition too, that in an era of increasing integration of financial markets and national and regional economies, through trade in goods and services, transfer of technology and production chains, that no single government has the power or the authority to impose a solution and that market forces alone will not solve the problem (Bhargava, 2006, p.2). With this recognition has come the notion of 'global public goods' defined by the International Task Force on Global Public Goods as goods and services that 'address issues that: (i) are deemed important to the international community to both developed and developing countries; (ii) typically cannot be adequately addressed by individual countries or entities acting alone; and in such cases are best addressed collectively on a multilateral basis. Included among these goods and services are environmental assets such as a stable world climate, energy, clean and fresh water, fisheries and forests which are deemed to be part of the global commons. ${ }^{14}$

Concomitant with the intensification and complexity of these global issues is the growing demand for reforms to make global governance systems within the UN and WTO, as well as within international financial institutions such as the International Monetary Fund (IMF), World Bank and Inter-American Development Bank (IADB), more effective and responsive. Embedded in this plethora of global issues are a host of challenges and opportunities for SIDS. Because decisions about the resolution or advancement of these issues are normally negotiated in global forums, SIDS are unable to participate effectively in these events and adequately to track emerging issues. The growing number and increasing complexity of international sustainable development agreements (ISDAs), and the amount of time consumed in their negotiation, are posing serious challenges for SIDS. While funding is normally made available to participate in these events, the opportunity cost of attending them is extremely high, especially for small and overburdened national delegations. SIDS delegations have argued that their ability to participate effectively in these conferences is 
affected by the way the meetings are structured and by their inability adequately to cover the large number of simultaneous committee/working group meetings that characterise these conferences. In some cases, SIDS delegations are not able to match the amount of preparation undertaken by their counterparts from the developed countries.

These challenges have led to intra-regional and inter-regional partnerships among SIDS involving inter alia, pooling of their scarce human, technical and financial resources to ensure qualitative and quantitative representation in various negotiating theatres especially those dealing with trade, and sustainable development issues. Concrete examples of this response include the establishment of the Caribbean Regional Negotiating Machinery (CRNM) to represent the interests of the Caribbean in negotiations on the Economic Partnership Agreement (EPA) with the European Union (EU), in which the CRNM acted in concert with Pacific and African SIDS in the context of the ACP grouping. Of interest too is the fact that the work of the CRNM continues to receive support from several international development partners such as Canadian International Development Agency (CIDA) and the EU.

The EPA marks a fundamental change in the character and structure of longstanding trade relations between the EU and ACP states. Essentially, it has replaced non-reciprocal trading arrangements for goods and services between states, which had existed for more than four decades, with a trade partnership. The EPA extends 100 per cent duty-free and quota-free market access to the EU from each region (with rules of origin provisions) while requiring ACP countries to open up their markets to a lesser extent, (on average 80 per cent) within 15 years. The agreement reached with CARIFORUM states has been roundly criticised in some quarters on legal, moral and technical grounds. More germane to the thrust of this chapter, however, are the concerns expressed about the rushed nature of the negotiations which did not allow for adequate consultation with partners at the national and regional level.

The EPA carries certain challenges for CARIFORUM states including a loss of tariff revenues (and thus requiring new forms of domestic tax and tax administration), complicated rules of origin that require simplification and liberalisation as well as fulfilment of EU standards and responding to enhanced market access. These criticisms and challenges suggest that the goals of a trade partnership between the EU and the CARIFORUM states will take some time to materialise.

Another concrete example of SIDS-SIDS co-operation is the Alliance of Small Islands States (AOSIS) details of which are shown in Box 1.2. Since its formation, AOSIS has played a critical and valiant role in negotiations of multilateral environmental agreements (MEAs) within the framework of the Conference of Parties (COPs) to the United Nations Framework Convention on Climate Change (UNFCCC) as well as UN Conferences on sustainable development issues. With support from UNDP (Capacity 2015) , $^{15}$, the Commonwealth Secretariat and CARICOM, AOSIS has been able to forge effective partnerships in many related areas such as research on renewable energy policy and technology, vulnerability and resilience, science and technology, water resources management and human resources management. Further collaboration is promised through the University Consortium of Small States (UCSIS) which was launched in January 2005 at the Mauritius International Meeting to review the Implementation of the Barbados Programme of Action. 
It is for its work on climate change that AOSIS is best known. Here partnerships have been forged at the political, diplomatic, technocratic and institutional levels, within and among SIDS. Inter-regional collaboration on climate research is on-going between the Caribbean Community Climate Change Centre (CCCCC) and the South Pacific Applied Geosciences Commission (SOPAC) and the Secretariat for the South Pacific Regional Environmental Programme (SPREP) (see Box 1.2 for background on the CCCCC). The CCCCC has built impressive technical and financial partnerships with a growing number of governments (including Japan, Italy, Greece and Trinidad and Tobago) and research institutions such as the UN Hadley Centre, INSMET of Cuba and Potsdam Climate Centre in Germany.

\section{Box 1.2 The Caribbean Community Climate Change Centre (CCCCC)}

The CCCCC was established in 2002, following a decision of the heads of CARICOM reached in July 2000. The Centre is a CARICOM institution whose purpose is to implement and co-ordinate activities for member countries stemming from the United Nations Framework Convention on Climate Change (UNFCCC). The Centre serves as an articulating mechanism for mainstreaming the climate change agenda into the way public and private institutions operate. Specifically, the Centre functions as:

- An advisory body to the CARICOM Secretariat and its member countries on climate change policy;

- A source of scientific and technical information on climate change and its potential impacts in the region;

- A co-ordinating body for climate change adaptation and mitigation activities, enhancing the institutional effectiveness and maximising synergies and cross-sectoral links among multiple stakeholders, national and regional institutions (public and private); and

- As a resource mobilisation and devolution institution for regional and national activities in the field of climate change.

\section{Box 1.3 The Alliance of Small Island States (AOSIS)}

AOSIS is a coalition of small, island, and low-lying coastal countries that share similar development challenges and concerns about the environment, especially their vulnerability to the adverse effects of global climate change. It functions primarily as an ad hoc lobby and negotiating voice on climate change and sustainable development issues within the United Nations system.

AOSIS has a membership of 43 countries and observers, drawn from all oceans and regions of the world: Africa, Caribbean, Indian Ocean, Mediterranean, Pacific and South China Sea. Thirtyseven states and observers are members of the United Nations; close to 28 per cent of developing countries, and 20 per cent of the UN's total membership. Together, SIDS communities constitute some five per cent of the global population.

Member states of AOSIS work together, primarily through their respective missions to the United Nations. AOSIS functions on the basis of consultation and consensus. Major policy decisions are taken during plenary sessions at ambassadorial level. The Alliance does not have a formal Charter. There is no regular budget, nor a Secretariat. With the Permanent Representative of Grenada as its current chair, AOSIS operates, as it did under previous chairs, out of the chair's mission to the United Nations. 
Effective participation in international meetings is, however, only a small part of the challenge. Most SIDS are experiencing extreme difficulty in creating the requisite policy and institutional framework to implement MEAs. The situation has not been helped by the fragmented nature of the institutional arrangements at the national level, nor by the lack of co-ordination and synergy among the various international conventions. While there are divergent views on the scope and seriousness of the implications of this fragmented governance for the effectiveness of MEAs, the Secretariats of the respective MEAs acknowledge that strengthened co-ordination has the potential to improve the output, outcomes and impacts of MEA effectiveness by promoting the coherence of rules and norms, sending mutually enforcing signals about behavioural change and ensuring the desired impacts of one regime on the environment do not undermine the impacts of another..

Addressing these problems will require aggressive legislative reform, a strong cadre of people trained in law, and strengthened technical capacity in the cross-sectoral demands of sustainable development. The situation also demands a sustained capacity-building effort to build a corps of competent negotiators in the mould of the CRNM to represent various SIDS regions at international environmental forums. The SIDS University Consortium should be invited to support this effort by designing and delivering modules in International Environmental Law and Environmental Diplomacy. Further, each region should design external relations strategies to facilitate the sustained involvement and the participation of regional diplomats assigned to international bodies, in negotiating ISDAs.

\section{The challenges of managing development assistance}

The heightened participation of SIDS in global negotiations has not brought about measureable increases in development assistance or in the transfer of appropriate technologies in key areas of vulnerability reduction and resilience building, such as renewable energy technologies (RETs). While new sources of funding have been created, including through the Global Environment Facility (GEF) and the Global AIDS Fund, development assistance to developing countries and to SIDS in particular has not met the target of 0.7 per cent of gross national income (GNI) pledged by members of the OECD and falls well short of the funding needed by the SIDS to build their resilience to climate change.

Ensuring the effective use of funds made available through bilateral, multilateral and global partnership arrangements has proven to be challenging for recipients and donors alike. Many SIDS do not have the requisite capacity simultaneously to handle multiple projects and to process the policy conditionalities attached to some types of development assistance. Many SIDS continue to insist that the totality and wide variety of donor requirements and processes for preparing, delivering and monitoring development assistance are generating unproductive transaction costs and deplete their limited capacity. Furthermore, the case has often been made that donor practices do not always fit well with national development priorities and systems including their budget, programmes and project planning cycles, public expenditure and financial management systems.

The international donor community has begun to heed these criticisms. The 2005 Paris Declaration on Aid Effectiveness, which builds on the 2003 Rome Declaration and the 2004 Roundtable on Managing for Development, was endorsed by officials from about 90 countries 
and 27 aid agencies. Consistent with the commitments given, the community has agreed to mutual accountability in carrying out the partnership agreements on both sides and has introduced a variety of measures to harmonise operational procedures at the highest standard. The key goals are to reduce transaction costs and make ODA and delivery more flexible, taking into account national development needs and objectives while emphasising country ownership, participation, partnership and a holistic approach to diagnosis and policy development. Aid for budgets and programmes rather than individual projects is also being stressed, coupled with the adaptation of instruments to deal with institutional capacity (OECD, 2003).

The Rome Declaration on Harmonisation conveys the acknowledgement of international donor agencies that, while their historical origins, institutional mandates, governance structures and authorising environments may vary, there is significant scope for simplifying and harmonising their requirements and reducing associated costs, while improving fiduciary oversight and public accountability as well as enhancing the focus on concrete development results. ${ }^{16}$ The agencies have committed to:

- Ensuring that development assistance is delivered in accordance with partner-country priorities, and that harmonisation efforts are adapted to the country context;

- Review and identify ways to amend individual countries' policies, procedures and practices to facilitate harmonisation;

- Work to reduce donor missions, reviews and reporting, to streamline conditionalities and simplify and harmonise documentation;

- Implement progressively, the good practices or principles in development assistance delivery and management, taking into account specific country circumstances;

- Intensify donor efforts to work through delegated co-operation at the country level and increase the flexibility of country-based staff to manage country programmes and projects more effectively;

- Provide support for country analyses in ways that will strengthen governments' ability to assume a greater leadership role and take ownership of development results;

- Work with partner governments to forge stronger partnerships and to improve the policy relevance, quality, delivery and efficiency of country analytic work;

- Provide budget sector, or balance-of-payments support where it is consistent with the mandate of the donor and when appropriate policy and fiduciary arrangements are in place; and

- Promote harmonised approaches in global and regional programmes.

However, the Independent Evaluation Group (IEG, 2007, p xvi-xvii) of the World Bank in a series of evaluations undertaken in 2007 found that, while many development issues call for partnerships among neighbouring countries, for example to manage water and other natural resources, to facilitate trade and transport, to provide for reliable sources of energy and to protect against the spread of disease, international development assistance is organised mainly to support programmes in individual countries with only 3 per cent of total aid devoted to regional programmes. Further, the IEG noted that, even though regional programmes are inherently more complicated than single country programmes, World Bank-supported programmes have been as effective in achieving their objectives as single 
country programmes. The success factors cited by the IEG for the superior performance of regional programmes include:

- Addressing the political economy of relations among neighbouring countries;

- Clear delineation and co-ordination of roles of national and regional organisations;

- Strong country commitment to regional co-operation;

- Matching scope of objectives with national and regional capacities; and

- Planning for long-term sustainability of programmes.

This is not to say that regional programmes do not present significant challenges. The IEG found that some countries participating in World Bank-supported regional programmes have shown little interest in paying for continued regional level activities, except when costs can by covered by self-generating revenue such as rents and licensing fees. The Management of the Bank in its response to the IEG Report cited the 'free-rider' problem whereby countries try to reap benefits without meeting the costs. While overcoming these challenges will not be easy, significant progress can be made through regular dialogue between donors and recipient countries. The framework for such dialogue exists in both the Caribbean and Pacific regions.

Interaction between the Caribbean and the international donor community is facilitated through biannual meetings of the Caribbean Forum for Development (CFD) formerly called the Caribbean Group for Cooperation in Economic Development (CGCED). The CGCED/CFD has made an important contribution to the three major objectives of resource mobilisation, aid co-ordination and policy dialogue between, on the one hand, the Caribbean's public and private sectors and the worldwide private sector. It has also helped to inform regional and national policy through the preparation of technical papers on a number of wide-ranging themes. Its analyses have helped to focus the attention of donors and governments alike on these core issues and have provided the necessary consensus for the emergence of successful regional programmes.

\section{Box 1.4 Pacific Aid Effectiveness Principles}

1. Country leadership and ownership of development through an accountable and transparent national development planning and financial management mechanism which is adequately resourced from the national budget including longer-term maintenance of donor sponsored development.

2. Multi-year commitments by development partners aligned to nationally identified priorities as articulated in national sustainable development strategies with agreement on performance indicators and monitoring and evaluation mechanisms.

3. Greater Pacific ownership of regional development.

4. Pacific development partners and countries pursue a co-ordinated approach in the delivery of assistance - encouraging harmonisation will be a priority for both.

5. Strengthen institutional mechanisms and capacity in countries to enable increased use of local systems by development partners.

6. Provision of technical assistance including for aid co-ordination in such a way as to ensure that capacity is built with tangible benefits to the country to support national ownership.

7. Use of an agreed monitoring framework that will ensure joint assessment of the implementation of agreed commitments on aid effectiveness. 
The Pacific region also has regular dialogue with its development partners as part of annual meetings of the PIF. This interaction is conditioned by the Pacific Aid Effectiveness Principles which are fashioned after the Rome and Paris Declarations (see Box 1.4 for details). Since 1989, the Forum has held post-Forum dialogues with key dialogue partners at ministerial level. There are currently 14 partners - The EU, Canada, Peoples' Republic of China, European Union, France, India, Indonesia, Italy, Japan, Republic of Korea, Malaysia, Philippines, Thailand, United Kingdom and the United States.

\section{Partnerships for bridging the technology divide}

Successive ISDAs have acknowledged that access to appropriate technology is absolutely crucial to resilience building in SIDS. Several national science and technology (S\&T) policies adopted in SIDS recognise that economic development and wealth creation activities, the development of agriculture, health systems, manufacturing and industry and the exploitation of natural resources, depend on the optimum use of appropriate technology. Yet apart from information and communications technology (ICT), SIDS have made very little progress in other areas of science and technology that might have a positive impact on disaster risk management, sustainable production and consumption, renewable energy technologies (RETs) and biotechnology and food production. With the exception of Mauritius, Singapore, Jamaica and Trinidad and Tobago, very few countries in the Caribbean, Pacific and Atlantic, Indian Ocean and South China Seas (AIMS) ${ }^{17}$ regions have well-established, functioning institutional arrangements for S\&T development. Jamaica has made steady progress towards the attainment of the objectives of its national science and technology

\section{Box 1.5 Jamaica's S\&T model}

The broad objective of Jamaica's S\&T policy is to increase the role of S\&T in the attainment of economic and social development by:

- Fostering, promoting and sustaining the development and the co-ordination of S\&T relevant to the needs and circumstances of the country;

- Establishing the conditions which will ensure scientific creativity and innovation and allow the talents of men and women to find full scope in scientific activity;

- Assessing, developing and managing the nation's natural resources;

- Utilising the results of world-wide research and development to strengthen productive sectors such as agriculture, industry and manufacturing;

- Ensuring that scientific and technological development improves the welfare of citizens;

- Protecting and improving the quality of the environment;

- Increasing the nation's competitiveness in trade;

- Enhancing the cultural, social and economic development of the country and contributing to programmes of self-reliance; and

- Supporting the integration of S\&T in macroeconomic planning.

The Policy identifies the following priority areas:

- Human resource development, science education, scientific and technological information, agriculture and food, nutrition and health, biotechnology, natural resources including mineral and marine resources, energy, trade and industry, employment opportunity, efficiency and productivity. 
policy (see Box 1.5), through the Science Research Council (SRC) and other entities such as the University of Technology (UT) and the International Centre for Environmental and Nuclear Sciences (ICENS). An impressive aspect of Jamaica's arrangement is the functional links between its S\&T agencies and its manufacturing sector.

\section{Recommendations}

An appropriate starting point for the design of effective partnerships would be for governments to embark on national visioning exercises to guide the design of national sustainable development strategies (NSDS). Appropriate cross-sectoral co-ordination mechanisms should be undertaken to streamline sustainable development initiatives. In that regard, NSDS should be made an integrating mechanism for the various sectoral development plans, prepared within each country. Also, sustainable development issues should be integrated into the everyday operations of the public sector.

Governments should consider establishing national sustainable development councils (NSDC), or a similar body of manageable size to co-ordinate sustainable development initiatives, including the preparation of the NSDS. The experiences of those countries where such bodies are successfully operating could be used to guide other countries wishing to pursue the establishment of such a body. Further, efforts should be made to ensure that NSDCs, at a minimum, include representatives of the private sector, trade unions, women, youth, the physically challenged and religious groups. Ideally, these councils should be backed by legislation and they should be given the means to undertake research into various development issues and concerns.

Extensive and sustained capacity building and national education and awareness programmes will be needed at all levels if participatory governance is to be routinely practiced. Long-term commitment by regional and international development partners is needed to strengthen generally weak, institutional and human resource capacity of the civil society actors. Further, the design of such programmes will need to be flexible and responsive to national or regional needs and political realities. In addition to strengthening the capacity of SIDS in the traditional domains of economic planning, social planning and physical and environmental planning respectively, it will also be necessary to build capacity in non-traditional areas, including regional planning, energy planning and management, resource economics, labour economics, policy analysis and policy management, telecommunications planning, science and technology management, conflict resolution and meeting facilitation.

Governments should consider facilitating decentralised decision making through local government authorities and or community councils. Ideally, these councils should be bodies elected through means other than the first-past-the-post system such as proportional representation. As has been shown in several Commonwealth countries, local government can make a significant contribution to the attainment of participatory governance and sustainable development. Inter-regional technical co-operation programmes can greatly assist in strengthening the capacities of SIDS to: 
- Establish the institutional and policy framework to undertake effective integrated development planning;

- Formulate inclusive and gender-sensitive social policies that can mitigate some of the social costs of globalisation; and

- Generate timely and reliable statistics on relevant economic, social, and environmental phenomena, including vulnerability indices.

The participation of developed countries with mature development planning capacity can be mobilised through regional and international intergovernmental organisations such as the Commonwealth Secretariat's Commonwealth Fund for Technical Co-operation (CFTC), the UN's Technical Cooperation between Developing Countries (TCDC), and the Organization of American States' (OAS) Fund for Integral Development (FEMCIDI) within the context of triangular co-operation. The Commonwealth Secretariat might be encouraged to mandate its Governance and Institutional Development Division (GIDD) to design and implement public sector reform initiatives that would advance the goals of PG and IGP in SIDS.

Partnerships between government, the private sector, trade unions and other civil society organisations in pursuit of regional development could best be achieved in an environment of enlightened participatory governance. However, it is unreasonable to expect this form of governance to emerge at the regional level if it does not exist at the national level. On paper, the infrastructure appears to exist to achieve this but, as has been inferred, governance is equally (if not more) about disposition and commitment as it is about laws, charters and institutions.

Regional SIDS groupings may wish to consider including annual outcomes-oriented processes with representatives from the private sector, academia and civil society organisations to provide feedback to leaders and to offer a platform for wide debate on regional development priorities.

The Commonwealth Parliamentary Association (CPA) can assist SIDS groupings by identifying best practice and by exploring with them models of participatory governance. The CPA might also consider establishing a study group for this purpose. Further, the CPA model might be employed at regional level to strengthen the capacity of parliamentarians in CARICOM, AIMS and PIF to play a leadership role in educating their constituencies and making them more aware of emerging developmental issues and challenges such as climate change and disaster risk management, and sustainable production and consumption. A fund should be set up to allow private sector and worker representatives to attend international meetings dealing with matters of interest to SIDS.

It is recommended that the Commonwealth Secretariat through the Commonwealth Partnership for Technology Management (CPTM) and in collaboration with its Small States Department and those of CFTC, UC-SIS, United Nations Industrial Development Organization (UNIDO), UNESCO and the OAS, undertake the design of a strategy aimed at achieving the objectives agreed at the Mauritius International Meeting on the review of the SIDS-Plan of Action (POA):

- Assisting SIDS in making critical technology choices; 
- Providing information on previous experiences in SIDS;

- Providing technical assistance to SIDS to help them develop institutional arrangements conducive to the registration of intellectual patents and the identification of potential partners for full-scale commercialisation;

- Undertaking an assessment of critical S\&T needs in SIDS that can be met in a costeffective manner;

- Continuing to strengthen S\&T collaboration through north-south and south-south co-operation; and

- Considering the establishment of a SIDS dedicated Technology Transfer Fund.

\section{Conclusion}

In examining the scope for effective partnerships for sustainable development of Caribbean and Pacific SIDS, this chapter has established the importance of seamless participatory governance at the national and regional levels, built around integrated developmentplanning principles and practice. The chapter argues that weaknesses at the national and regional levels in this area, in particular the absence of development plans that are designed with full participation by the private sector, trade unions and other civil society actors are at the root of slow progress and explain the minimal impact of policy interventions in critical areas of sustainable development in SIDS. The chapter calls for sustained commitment by all actors in the development process to establish firm and lasting partnerships aiming to reduce the vulnerability and to build the resilience of SIDS.

\section{Notes}

1. Quoted by D Venner in 'Sub-regional Governance: The OECS Experience' (2003). In Governance in the Age of Globalization: Caribbean Perspectives by K Hall and D Benn (eds.) Kingston Jamaica: Ian Randle Publishers.

2. Extracted from: http://www.oecd.org/topic/0,2686,en_2649_37405_1_1_1_1_37405,00.html [last accessed July 2011].

3. Organisation of Eastern Caribbean States (OECS), Castries, St Lucia (1998).

4. These include religions and religious organisations; not-for-profit foundations, trade unions and employee organisations; non-governmental organisations; community-based organisations and organisations of indigenous peoples.

5. See: http://siteresources.worldbank.org/CSO/Resources/WorkingTogetherBooklet.pdf [accessed July 2011].

6. The Forum's membership includes its original seven founding members (Australia, Cook Islands, Fiji, Nauru, New Zealand, Tonga and Western Samoa - now Samoa) and the Federated States of Micronesia, Kiribati, Niue, Republic of the Marshall Islands, Palau, Papua New Guinea, Solomon Islands, Tuvalu and Vanuatu. New Caledonia and French Polynesia, previously Forum Observers, were granted Associate Membership in 2006. Current Forum Observers include Tokelau (2005), Wallis and Futuna (2006), the Commonwealth (2006) and the Asia Development Bank (2006), with Timor-Leste as Special Observer (2002). 
7. The member countries are Antigua and Barbuda, The Bahamas, Barbados, Belize, Dominica, Grenada, Guyana, Haiti, Jamaica, Montserrat, St Kitts and Nevis, St Lucia, St Vincent and the Grenadines, Suriname and Trinidad and Tobago.

8. Charter of Civil Society for the Caribbean Community (CARICOM Charter on Civil Society), preamble, 19 February 1997, available at: http://actrav.itcilo.org/actrav-english/telearn/global/ilo/ blokit/caricha.htm [accessed July 2011].

9. See CIEL (2003). Participation, Information Justice,www.cedha.org.ar/docs/doc108-eng.doc [last accessed May 2011].

10. Caribbean Community Secretariat (2002). The Liliendaal Statement of Principles on 'Forward Together', July 2002.

11. Report of Technical Working Group on Governance appointed by CARICOM Heads of Government, October 2006 available at: http://www.caricom.org/jsp/community/twg_governance_report.pdf [last accessed July 2011].

12. See www.forumsec.org.fj/resources/uploads/attachments/documents/PICTA.pdf [last accessed July 2011].

13. http://unfccc.int/kyoto_protocol/mechanisms/clean_development_mechanism/items/2718.php [last accessed July 2011].

14. See International Task Force on Global Goods and Services at: http://www.globalcollab.org/gps/ applied-gps/global-public-goods-2/what-gpg [last accessed July 2011].

15. Capacity 2015 is a global partnership mechanism assisting countries to develop the capacity of their professionals, institutions and systems to formulate and implement strategies for sustainable development to achieve local, national and international development goals. One of the components of Capacity 2015 is specifically focused on sustainable development challenges in small island developing states.

16. The Rome Declaration was endorsed in February 2003 by ministers, heads of aid agencies and other senior officials representing 28 aid-recipient countries and more than 40 multilateral and bilateral development institutions.

17. This title derives from the initial letters of the marine areas in which the islands in the AIMS region are located: Atlantic, (Guinea Bissau, Cape Verde, Sao Tome, Principe), Indian Ocean (Bahrain, Comoros, Maldives, Mauritius, Seychelles), Mediterranean (Cyprus, Malta) and South China Seas (Singapore).

\section{References}

Bhargava, V (2006). Introduction to Global Issues in Global Issues for Global Citizens: An Introduction to Key Development Challenges. Washington, DC: World Bank.

Briguglio, L (2004). Economic Vulnerability and Resilience of Small States, Short Paper presented at SIDS InterRegional Meeting, University of Malta, January 2004.

Byron, J (2003). 'Rethinking International Relations: Changing Paradigms for More of the Same?' In Governance in the Age of Globalization: Caribbean Perspectives by K Hall and D Benn (eds.) Kingston, Jamaica: Ian Randle Publishers.

Caribbean Community (CARICOM). (2006) Report of Technical Working Group on Governance, October 2006. Turkeyen, Guyana: CARICOM Secretariat.

CIEL (2006). Participation, Information and Justice, (draft), CIEL, London 
Lewis, V (2003). 'Regional Institutional Arrangements: Underlying Assumptions and Contemporary Appropriateness'. In Governance in the Age of Globalization: Caribbean Perspectives by K Hall and D Benn (eds.) Kingston, Jamaica: Ian Randle Publishers.

Lewis, William Arthur (1965). The Agony of the Eight. Barbados: Advocate Commercial Printers.

Organisation of Eastern Caribbean States (OECS) (1998). An Integrated Approach to Development in the OECS: Towards a Paradigm Shift. St Lucia: OECS Secretariat.

OECS (2004). Regional Caribbean Workshop on National Sustainable Development Strategies and Indicators of Sustainable Development, Castries, St Lucia 14-15 January 2004.

Organisation for Economic Co-operation and Development (n.d). Available at: http://www.oecd.org/ topic/0,2686,en_2649_37405_1_1_1_1_37405,00.html [last accessed July 2011].

Shah, R (2004). Indicators for Sustainable Development: Principles and Practice. Presentation at Regional Caribbean Workshop on National Sustainable Development Strategies and Indicators of Sustainable Development, Castries, St Lucia, 14-15 January 2004.

Singh, N (2003). 'Governance for Poverty Eradication and Sustainable Development'. In Governance in the Age of Globalization: Caribbean Perspectives by K Hall and D Benn (eds.) Kingston, Jamaica: Ian Randle Publishers.

United Nations (2005). Report of the UN Secretary-General to the UN General Assembly on Enhanced Cooperation between the UN and all Relevant Partners in Particular the Private Sector, Document A/60/214. New York: UN.

United Nations Development Programme (UNDP) (1997). Governance for Sustainable Human Development. New York: Bureau for Policy and Programme Support, January 1997.

United Nations University (UNU) (1999). Inter-linkages: Synergies and Coordination between Multilateral Environmental Agreements. Shibuya-ku, Tokyo, Japan: United Nations University.

World Bank (2007). The Development Potential of Regional Programmes: An Evaluation of World Bank Support of Multi-country Operations. Washington, DC: Independent Evaluation Group.

World Business Council on Sustainable Development (1998). Meeting Changing Expectations. Geneva, Switzerland: WBCSD Publications. 